\title{
Hamartoma Epithelial Respiratory Adenomatoid- Literature Review
}

\author{
Eduardo Machado Rossi Monteiro*, Lívia Bernardi Lopes, Carolina Batista e Silva, Flávia Amarante \\ Cardoso, Marianna Novaes da Costa Ávila and Bernardo Scarioli Oliveira
}

Department of Otorhinolaryngology, Felício Rocho Hospital, Brazil

*Corresponding author: Eduardo Machado Rossi Monteiro, Department of Otorhinolaryngology, Felício Rocho Hospital, Belo Horizonte, MG, Brazil.
Received Date: May 07, 2020

Published Date: May 19, 2020

\begin{abstract}
Hamartoma (from the Greek, Hamartia, meaning fault or defect) is used to describe an overgrowth of normal mature cells and tissues indigenous to the area of its occurrence. It may occur in any organ of the body. Wenig and Heffner described a series of 31 cases of Respiratory Epithelial Adenomatoid Hamartoma (REAH) from what they considered a benign neoplasm. Today the most acceptable hypothesis is that REAH is a hyperplasia of the respiratory epithelium induced by a local chronic inflammation. Since its publishing, 394 cases of the disease have been described and REAH was found in 35-48\% of patients operated on for nasal polypose. Some authors believe that REAH is the most important differential diagnosis of nasal polypose. REAH can be observed in two forms: isolated REAH (less frequent) or in association with another inflammatory process. The location in the olfactory cleft is concisely described in literature. Patients with REAH exhibit similar symptoms to those with chronic nasal inflammatory diseases. Endoscopy usually reveals a mass with a slight cerebriform aspect, fleshy to firm, pinkish or sometimes yellowish. The mass typically emerges from the cleft between the nasal septum superior-anterior and the middle turbinates, with a lateralization of the middle turbinates. Computed tomography (CT) scan is essential to diagnosis suspicion, which is increased by a CT scan that shows opacified and widened olfactory clefts. The conclusive diagnosis is only made by biopsies. Surgical treatment of the olfactory cleft is reported to be curative for REAH and the literature have also not described any recurrence or malignization. The knowledge of this lesion, mostly underdiagnosed, will allow the correct and necessary treatment that it takes.
\end{abstract}

Keywords: Respiratory ephitelial adenomatoid hamartoma; REAH; Differential diagnosis; Nasal polypose

\section{Introduction}

The Hamartoma Epithelial Respiratory Adenomatoid (HERA), better known by the initials REAH (Respiratory Epithelial adenomatoid hamartoma) in Anglo-Saxon literature, was first described in 1995 by Wenig and Heffner as a benign tumor of the nose and sinus cavities [1]. As it is an injury rarely described in the national literature, and in order to facilitate future literature searches, the initials adopted in this review to refer to Hamartoma Epithelial Respiratory Adenomatoid will be REAH. What seemed to be a rare injury, in fact it was an injury underdiagnosed and unknown to most of otolaryngologists, radiologists and pathologists. From 1995, year of its description to 2013, 394 cases of the REAH disease have been described and it was observed in $35-48 \%$ of patients undergoing nasosinusal polyposis surgery [2]. Some authors believe that the REAH is the most important differential diagnosis of nasosinusal polyposis [2].

\section{Review of A Particular Subject}

\section{Clinicopathological findings}

The term hamartoma (from the Greek, Hamartia, meaning fault or defect) is used to designate an overgrowth of disorganized tissue indisgenous to the area of its occurrence. They can occur in any tissue in the body [3]. When their series of 31 cases was described, Wenig and Heffner thought it was a benign tumor. Microscopically, they are characterized by a medium-sized pseudoglands proliferation, oval or round, surrounded by interstitial tissue of the respiratory ciliated pseudostratified epithelium, which 
invaginates the submucosa and continues with the surface of the epithelium. The glands are typically surrounded by a thick basal membrane eosinophilic [2] (Figure 1). Studies suggest that mast cells play an important role in the development of the REAH. Immunohistochemistry is not useful for the diagnosis [4]. In 2005, REAH was added to the World Health Organization tumors index, although there are controversies, today, the most accepted hypothesis is that the REAH is a respiratory epithelial hyperplasia in response to local chronic inflammatory process [5]. In 2006 Lima et al. [6] confirmed the origin of REAH the olfactory cleft, although other locations have also been described. Clinically the symptoms are similar to other inflammatory diseases of the nose, such as nasal obstruction, rhinorrhea, facial pain or pressure, headache, and hyposmia/anosmia [6]. Nasal obstruction and anosmia are the most frequent [7, 8]. Endoscopy usually reveals bilateral, often asymmetrical or unilateral nasal masses, with the lesion a cerebriform aspect, consistent, pinkish to yellowish emerging between the septum and the middle turbinates (Figure 2). In a recent review, Nguyen et al. [2] found an association of REAH and nasosinusal polyposis in 57\% of cases [2]. REAH can be observed in two forms: Isolated (less frequent) and in association with other nasal inflammation, most commonly, naso-sinusal polyposis. REAH was found in $35-48 \%$ of polyposis surgery. The disease is observed from the third to ninth decade of life, predominantly in the fifth decade, with a male/women ratio of 3: 22 .

Figure 1

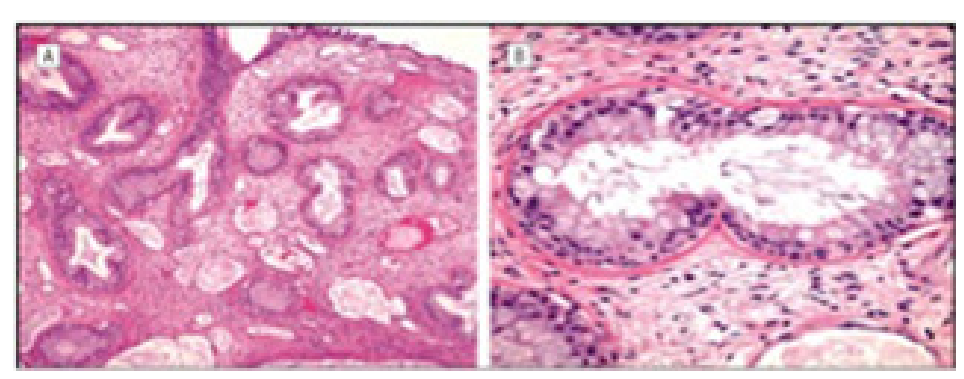

Figure 2
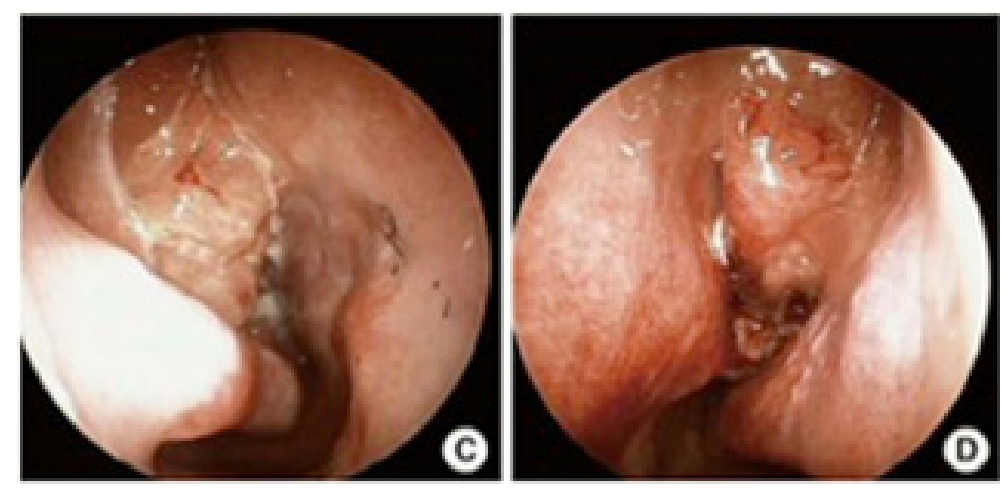

\section{Etiological findings}

There was no association found between REAH and environmental or occupational agents, such as smoking or alcohol consumption. Several studies have defined the association of REAH and nasosinusal polyposis [2]. In a prospective study Nguyen et al. found a highly association between REAH and long duration of nasosinusal polyposis, repeated sinus surgery and asthma [9]. Others authors suggest association REAH with adenoiditis, hereditary hemorrhagic telangiectasia, allergic rinossinusopatias and even malignant naso-sinusal tumors [2].

\section{Radiological findings}

The CT scan is indispensable for the diagnostic suspicion. In the absence of drug treatment CT scan can reveal images compatible with nasosinusal polyposis, with major or minor sinus opacities. After drug treatment with antibiotics and steroids, CT can show improvement or even disappearance of sinus opacification, persisting the opacity of the olfactory cleft, which appears enlarged middle turbinate away laterally (Figure 3). In axial sections, especially in the anterior half, the enlargement of the olfactory cleft is evident, dislocating the middle turbinate and ethmoid cells toward orbital wall [10]. In a retrospective analysis of CT scans Lima et al. [6] found a median of $12 \mathrm{~mm}$ in size of both olfactory slots for REAH against $5 \mathrm{~mm}$ in nasosinusal polyposis and $4 \mathrm{~mm}$ in the control group. This homogeneous opacity can mimic other benign or malignant nasal lesions, but in REAH usually is not found defects or erosion of the skull base [6]. In case of doubt, a preoperative biopsy is clarifying and allows better surgical planning. Magnetic resonance imaging helps in the differential diagnosis for isolated and unilaterally REAH with inverted papilloma, meningoencephalocele and malignant tumors. In addition, MRI also helps to distinguish the lesion from mucous retention [2]. However a conclusive diagnosis is only available after histopathological examination. 
Figure 3

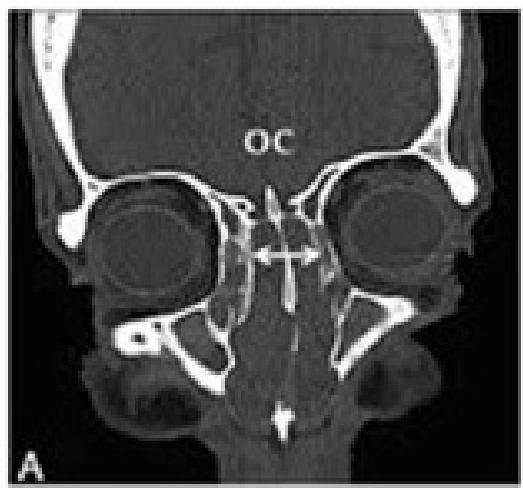

\section{Differential diagnosis}

Inflammatory polyps, papilloma, hemangioma, glioma, squamous cell carcinoma, olfactory neuroblastomas, lymphomas, and especially inverted papillomas and adenocarcinomas [2].

\section{Treatment}

Most authors recommend conservative surgical treatment of REAH, since the injury does not respond to medical treatment with local or systemic corticosteroids [8]. Besides, spontaneous regression or malignant transformation of the lesion are not described [2]. Boulanger et al. [11] describe the surgical steps as follows:

1) Debulking of the tumor until the middle turbinate is identified.

2) Ethmoidectomy: It begins with a dissection of the medial wall of the orbit, followed by dissection of the ethmoid roof, from the frontal sinus ostium to the sphenoid sinus. Resection of the middle turbinate, keeping the upper turbinate.

3) Resection of the olfactory cavity starts with an anterior hemitransfixiant incision of the nasal septum with subperichondral/ subperiosteal detachment with lifting the septal mucosa of the nasal floor, inferiorly, to the cribriform plate, superiorly, and the face of the sphenoid posteriorly. Next, the middle turbinate is fractured in its attachment to the cribriform plate; in this procedure the olfactory fibers are sectioned at their emergence from the cribriform plate from anterior to posterior. At this point the mucosa of the olfactory cleft is easily detached from its bone roof, allowing the complete injury resection [11].

In cases of skull base procedures, there is a potential risk of cerebrospinal fluid leaks as a complication, so, the surgeon must be able to recognize and manage it [11]. In the hands of experienced surgeons the surgery seems to get good results, especially in cases of REAH associated with nasosinusal polyposis. Nguyen et al. established in prospective studies that surgery does not worsen the olfactory cleft smell, unlikely only $45.1 \%$ of patients with hyposmia/anosmia obtained smell sense improvement [12]. Similar results were found in REAH surgery associated with polyposis.

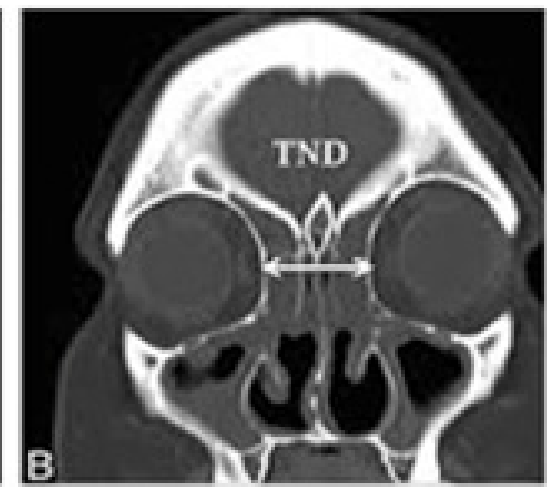

The best results, however, seem to be related to nasal obstruction improvement, especially in cases associated with polyposis [7]. Recurrences are rare and the surgery seems to be healing [2].

\section{Discussion}

Sinonasal hamartomas are an extremely rare entity, with the subtype of REAHs only being described less than 20 years ago. Symptoms at presentation are similar to those affecting patients with nasosinusal inflammatory diseases, including nasal congestion, nasal obstruction, headaches, facial pain, epistaxis, and hyposmia [6]. In our data, the findings were consistent with symptoms suggestive of chronic sinusitis with no pathognomonic symptoms to specifically suggest REAH. In addition, there is highly association between REAH and long duration of nasosinusal polyposis, chronic allergic sinusitis, repeated sinus surgery and asthma [9].

Similarly, there were no distinguishing features on endoscopic examination to suggest a diagnosis of REAH, and there was no characteristic appearance or specific signal intensity on CT or magnetic resonance imaging to help distinguish REAH from other sinus pathology. REAH is an important entity that must be distinguished from other diagnoses in the nasal cavity and paranasal sinuses, which may be confused with REAH. The differential diagnosis of REAH includes inflammatory polyps, inverted papilloma, and especially low-grade adenocarcinoma. Histopathologic examination of the tissue is necessary to differentiate these different disease entities and to plan the correct clinical and/or surgical treatment $[12,13]$.

The treatment of REAH consists of conservative surgery. Because hamartomas do not have a malignant potential, complete excision is essentially curative and recurrences are rare. Misdiagnose of REAH with these other entities, such as inflammatory polyps, inverted papillomas, and low-grade adenocarcinoma can lead to unnecessary more extensive surgical interventions [14]. In contrast, mistaking other more aggressive pathology for REAH may lead to incomplete resections without clear margins.

\section{Final Comments}

Since its description in 1995, REAH appeared to be a rare injury and only found in sporadic case reports. It is now known that it is an 
underdiagnosed and unknown injury to most of otolaryngologists, radiologists and pathologists. The knowledge of this important entity, present in up to $48 \%$ of polyposis surgeries, allows the appropriate treatment and the resolution of symptoms in most cases.

\section{Acknowledgement}

None.

\section{Conflict of Interest}

No conflict of interest.

\section{References}

1. Wenig BM, Heffner DK (1995) Respiratory epithelial adenomatoid hamartomas of the sinonasal tract and nasopharynx: A clinic pathologic study of 31 cases. Ann Otol Rhinol Laryngol 104: 639-645.

2. Nguyen DT, Gauchotte G, Arous F, Vignaud JM, Jankowski R (2014) Respiratory epithelial adenomatoid hamartoma of the nose: An updated review. Am J Rhinol Allergy 28: e187-e192.

3. Vira D, Bhuta S, Wang MB (2011) Respiratory epithelial adenomatoid hamartomas. Laryngoscope 121: 2706-2709.

4. Gauchotte G, Marie B, Gallet P, et al. (2013) Respiratory epithelial adenomatoid hamartoma: A poorly recognized entity with mast cell recruitment and frequently associated with nasal polyposis. Am J SurgPathol 37: 1678-1685.

5. Barnes L, Eveson JW, Reichart P, et al. (Eds.) (2005) Respiratory epithelial adenomatoid hamartoma. In WHO Classification of Tumours Pathology and Genetics of Head and Neck Tumours. Lyon, IARC Press, 33, France.
6. Lima NB, Jankowski R, Georgel T, Grignon B, Guillemin F, Vignaud JM (2006) Respiratory adenomatoid hamartoma must be suspected on CTscan enlargement of the olfactory clefts. Rhinology 44: 264-269.

7. Nguyen DT, Bey A, Arous F, Nguyen-Thi PL, Felix-Ravelo M, et al. (2015) Can Surgeons Predict the Olfactory Outcomes After Endoscopic Surgery for Nasal Polyposis? Laryngoscope 125(7):1535-1540.

8. Lorentz C, Marie B, Vignaud JM, Jankowski R (2012) Respiratory epithelial adenomatoid hamartomas of the olfactory clefts. Eur Arch Otorhinolaryngol 269:847-852.

9. Nguyen DT, Nguyen-Thi PL, Gauchotte G, Arous F, Vignaud JM, Jankowski R (2014) Predictors of Respiratory Epithelial Adenomatoid Hamartomas of the Olfactory Clefts in Patients With Nasal Polyposis. Laryngoscope 124: $2461-2465$

10. Georgel T, Jankowski R, Vignaud JM, Dugny O, Weinbreck N, et al. (2007) Hamartomes adénomatoïdes des fentes olfactives. Fr ORL 92: 274-281.

11. Boulanger N, Grosjean R, Jankowski R (2011) Pathology of tumours originating in the olfactory cleft. B-ENT 7 Suppl 17: 21-25.

12. Nguyen, DT, Gauchotte G, Nguyen-Thi PL, Jankowski R (2013) Can Surgeons Predict the Olfactory Outcomes After Endoscopic Surgery for Nasal Polyposis? Am J Rhinol Allergy 27: 317-321.

13. Hua et al. (2014) Clinicopathological and EBV analysis of respiratory epithelial adenomatoid hamartoma. Diagnostic Pathology 9: 70.

14. RA Khan, RD Chernock, JS Lewis (2011) Seromucinous Hamartoma of the Nasal Cavity: A Report of Two Cases and Review of the Literature. Head and Neck Pathol 5: 241-247. 